\title{
Cognitive Control and Brain Network Dynamics during Word Generation Tasks Predicted Using a Novel Event-Related Deep Brain Activity Method
}

\author{
Emiko Imai ${ }^{*}$, Yoshitada Katagiri ${ }^{1,2}$ \\ ${ }^{1}$ Department of Rehabilitation Science, Kobe University Graduate School of Health Science, Hyogo, Japan \\ ${ }^{2}$ Advanced ICT Research Institute, National Institute of Information and Communication Technology, Tokyo, Japan \\ Email: ^e-imai@stu.kobe-u.ac.jp
}

How to cite this paper: Imai, E. and Katagiri, Y. (2018) Cognitive Control and Brain Network Dynamics during Word Generation Tasks Predicted Using a Novel EventRelated Deep Brain Activity Method. Journal of Behavioral and Brain Science, 8 , 93-115.

https://doi.org/10.4236/jbbs.2018.82006

Received: January 2, 2018

Accepted: February 23, 2018

Published: February 26, 2018

Copyright $\odot 2018$ by authors and Scientific Research Publishing Inc. This work is licensed under the Creative Commons Attribution International License (CC BY 4.0).

http://creativecommons.org/licenses/by/4.0/

\begin{abstract}
There is a growing interest in the diagnosis and treatment of patients with dementia and cognitive impairment at an early stage. Recent imaging studies have explored neural mechanisms underlying cognitive dysfunction based on brain network architecture and functioning. The dorsal anterior cingulate cortex (dACC) is thought to regulate large-scale intrinsic brain networks, and plays a primary role in cognitive processing with the anterior insular cortex (aIC), thus providing salience functions. Although neural mechanisms have been elucidated at the connectivity level by imaging studies, their understanding at the activity level still remains unclear because of limited time-based resolution of conventional imaging techniques. In this study, we investigated temporal activity of the dACC during word (verb) generation tasks based on our newly developed event-related deep brain activity (ER-DBA) method using occipital electroencephalogram (EEG) alpha-2 powers with a time resolution of a few hundred milliseconds. The dACC exhibited dip-like temporal waveforms indicating deactivation in an initial stage of each trial when appropriate verbs were successfully generated. By contrast, monotonous increase was observed for incorrect responses and a decrease was detected for no responses. The dip depth was correlated with the percentage of success. Additionally, the dip depth linearly increased with increasing slow component of the DBA index at rest across all subjects. These findings suggest that dACC deactivation is essential for cognitive processing, whereas its activation is required for goal-oriented behavioral outputs, such as cued speech. Such dACC functioning, represented by the dip depth, is supported by the activity of the upper brainstem region including monoaminergic neural systems.
\end{abstract}




\section{Keywords}

Deep Brain Activity, Alpha-2 Wave, Cognitive Processing, Dorsal Anterior Cingulate Cortex, Event-Related Deep Brain Activity Method

\section{Introduction}

Cognitive control is essential for performing daily activities. It allows the brain to vary adaptive behavior according to current goals and tasks, rather than remaining rigid and inflexible. Cognitive behavior is altered, in a number of neurodegenerative and psychiatric diseases, lowering the quality of life. Enormous effort has been addressed to eliciting underlying neurophysiological mechanisms of the affected individual [1]-[8]. Functional magnetic resonance imaging (fMRI) studies reveal that neurophysiological mechanisms underlying cognitive disorders involve disrupted large-scale brain networks, including the default mode network (DMN) consisting of the ventromedial prefrontal cortex (VmPFC), posterior cingulate cortex (PCC), inferior parietal lobule, and hippocampus; the salience network (SN) consisting of the dorsal anterior cingulate cortex (dACC) and insular; and the central executive network (CEN) consisting of the dorsolateral prefrontal cortex (DLPFC) and intra-parietal sulcus (IPS) [9]-[18].

To elicit mechanisms of cognitive dysfunction, there has been a significant interest in understanding networks that manage cognitive function. Recent fMRI studies have revealed a negative correlation between the DMN, a task-negative network, and the CEN, a task-positive network [19] [20] [21] [22]. However, these networks are not always anti-correlated [23] [24] [25] [26]. Such counterevidence to the conventional anti-correlation-based brain network architectures [27] is thought to originate from dynamic interactions [28]. Using a graph theory [29] [30], correlations across the entire brain have been investigated using fMRI data measured both during rest and while actively performing tasks to explore how the human brain is functionally organized [31] [32].

Although the brain intrinsically follows an anti-correlated architecture, the organized networks are reconfigurably associated with not only aging [33] but also external situations [34] [35] [36]. To understand mechanisms underlying contextual reconfiguration of brain networks, an event-related fMRI paradigm has been developed [37] [38]. Data given by this paradigm reflect temporal information associated with hemodynamics. To elicit the mechanisms, such data are desired to be integrated with data derived from more direct electrophysiological measurements including electroencephalography [39]. However, blood oxygen level dependent signals of fMRI are too slow to capture temporally changing network dynamics, compared with electroencephalogram (EEG) signals. This discrepancy interferes with the integration of fMRI and EEG paradigms. 
In this study, we aimed to investigate temporal behavior of dACC for exploring the temporal dynamics of task-oriented brain networks recruited for cognitive processing. We adopted a single word generation task [40] [41] [42] following conventional trial-by-trial protocols, where subjects were asked to pronounce a semantically appropriate verb for a presented noun at each trial. It is well known that the left inferior prefrontal cortex (IPFC) and dACC are activated during word generation tasks. This activation of AACC and IPFC is attributed to semantic processing and target-oriented attention control, respectively [43]. Therefore, to elicit the dynamics of cognitive processing for generating contextual verbs, the dACC was considered as the target to measure during tasks.

We adopted an electroencephalographic (EEG) technique for numerically evaluating the activity of AACC in the derivations of the occipital EEG alpha-2 $(10-13 \mathrm{~Hz})$ power fluctuations. The occipital EEG alpha rhythms were thought to come from neocortical structures, and enormous effort had been addressed to explore which areas are correlated with the EEG alpha rhythms [44] [45] [46] [47]. More recently, it has been shown that regional activity is dependent on the frequency range of the occipital alpha-2 power fluctuations; a faster component $(\geq 0.04 \mathrm{~Hz})$ represents the metabolic activity of dACC, whereas a slower component $(\leq 0.04 \mathrm{~Hz})$ represents the upper brainstem [48]. Based on this finding, we developed an event-related deep brain activity (ER-DBA) assessment paradigm using trial-by-trial tasks. This paradigm provides event-related traces in the derivation of the arithmetic mean of alpha-2 power streams with a high time resolution of hundreds of ms. This enabled numerical evaluation of the temporal activity of dACC as a member of the deep brain structures, for the first time, beyond the capability of conventional event-related fMRI techniques.

\section{Materials and Methods}

\subsection{Subjects}

Student volunteers from the Kobe Co-medical College (grade: $1^{\text {st }}$, major: training course for speech-language-hearing therapy) were screened for their medical history declared in clinical interviews, and students currently receiving treatment for neurological and/or psychiatric disorders were eliminated. Twelve healthy subjects ( 6 males and 6 females; mean age $25.0 \pm 1.8$ years) were selected to participate in this study according to a criterion stating that subjects should be native Japanese speakers who grew up in Japan. Written informed consent was obtained from subjects according to the guidelines of the ethics committee of Kobe University Graduate School of Health Sciences.

\subsection{Stimuli}

A series of auditory stimuli consisting of 60 pairs of sounds S1 and S2 were used for this study (Figure 1). S1 represented the sound of a single familiar Japanese noun, while S2 was a beep sound used as a speech onset cue. Sounds S1 and S2 


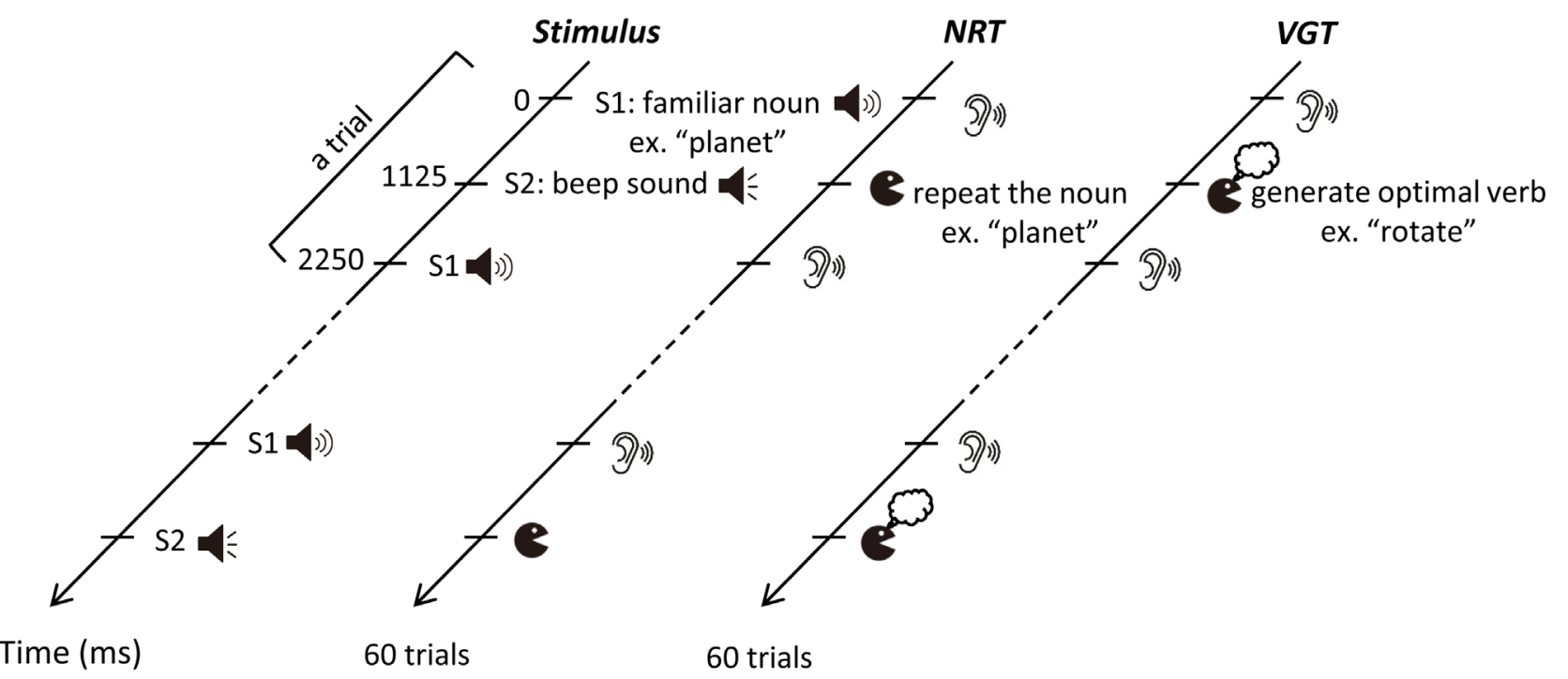

Figure 1. Schematic representation of a series of auditory stimuli and paradigm design [40] for noun repetition task (NRT) and verb generation task (VGT).

were separated by an interval of $1125 \mathrm{~ms}$. Nouns were pronounced with natural prosodies, and each beep sound had a duration of $50 \mathrm{~ms}$ at $2000 \mathrm{~Hz}$. Each trial comprised of an S1 and an S2 sound and was $2250 \mathrm{~ms}$ long.

\subsection{Paradigm Design}

Subjects were asked to respond to auditory instructions, according to which they were expected to repeat the noun (noun repetition task; NRT) or generate the associated verb (verb generation task; VGT) as soon as they heard the beep sound. The verbal response of each subject was recorded using a digital voice recorder. Scalp EEG of the subjects were recorded Scalp EEGs were also recorded with using $\mathrm{Ag} / \mathrm{AgCl}$ electrodes arranged according to the international 10 - 20 method. The EEG recordings were carried out with a digital electroencephalograph, which provided recording channels with a 24-bit voltage resolution and a sampling rate of $512 \mathrm{~Hz}$. The EEG signals were re-referenced to the mastoid electrodes (A1 and A2) and band-pass filtered in the $0.1-45 \mathrm{~Hz}$ range to eliminate artifacts. EEG recording during tasks was performed with the eyes closed.

\subsection{Behavioral Performance Analysis}

Verbal responses of subjects were analyzed linguistically and prosodically, and categorized into three behavioral groups: correct response (CR), incorrect response (IR), and no responses (NR) groups. The response of a subject was categorized as IR if it was linguistically incorrect, e.g., an adjective, instead of a verb, was generated by the subject or a different verb, not relatively close to the noun, was generated; or prosodically incorrect, e.g., the response exhibited an abnormal rhythm, such as stuttering or partially repeating the same word. Examples of linguistic and prosodic errors are provided in Table 1. If no response was recorded in the voice recorder, it was categorized as NR. 
Table 1. Examples of error assessment.

\begin{tabular}{ccc}
\hline Stimulus & Response & Assessment \\
\hline Blood pressure & High & Grammatical error: adjective generation \\
Pine cricket & Eat & Perseveration: the same verb generation \\
Alarm & s-set & Abnormal rhythm: stuttering \\
\hline
\end{tabular}

\subsection{EEG Data Analysis}

Occipital EEG alpha-2 powers were numerically extracted at both $\mathrm{O} 1$ and $\mathrm{O} 2$ sites using a digital band-pass $(10-13 \mathrm{~Hz})$ filter in a 2-s epoch. DBA index was defined as an average of two time series' signals. The DBA index waveforms observed in a window of $2200 \mathrm{~ms}$ were considered as the fast component of DBA, indicating the dACC activity, whereas average DBA indices in a larger time span of $>25$ s corresponding to the frequency of $0.04 \mathrm{~Hz}$ represented the slow component of DBA, indicating the upper brain-stem activities. The slow component of DBA indices was used for explaining personal differences in cognitive performance, whereas the fast component was used for investigating network dynamics during cognitive processing.

\subsection{Event-Related DBA Index Analysis}

An event-related design, which can be applied to the fast component of DBA indices, was developed following a conventional event-related potential (ERP) paradigm. Additional processing was performed with data extracted in a limited time range of approximately $2 \mathrm{~s}$ from original DBA index data based on S1 as event markers, excluding outliers. The averaged temporal waveforms were defined as event-related (ER) DBA indices (Figure 2). Baseline correction was performed $200 \mathrm{~ms}$ prior to the onset of noun presentation (S1). The event-related features of dACC activities were numerically estimated using the ER-DBA indices, avoiding background spontaneous brain activities. The time resolution was expected to be approximately $0.3 \mathrm{~s}$, taking into account that the alpha-2 $(10-13 \mathrm{~Hz})$ frequency band was regarded as an occupied single-side-band modulation band including temporal information [49] ER-DBA index traces under this time resolution were expected to distinguish between a few events per second.

Here, performance-dependent ER-DBA indices were used to examine the temporal dACC activity patterns during cognitive processing and elucidate the underlying network dynamics. A conventional subtraction technique used widely for analyzing ERP data [50] was applied to the two ER-DBA indices measured during NRT and VGT. The VGT was assumed to involve additional cognitive processing of memory retrieval and decision-making associated with the generation of an optimal verb. Thus, the subtracted ER-DBA indices would indicate brain activities related to additional cognitive processing during VGT [51]. 


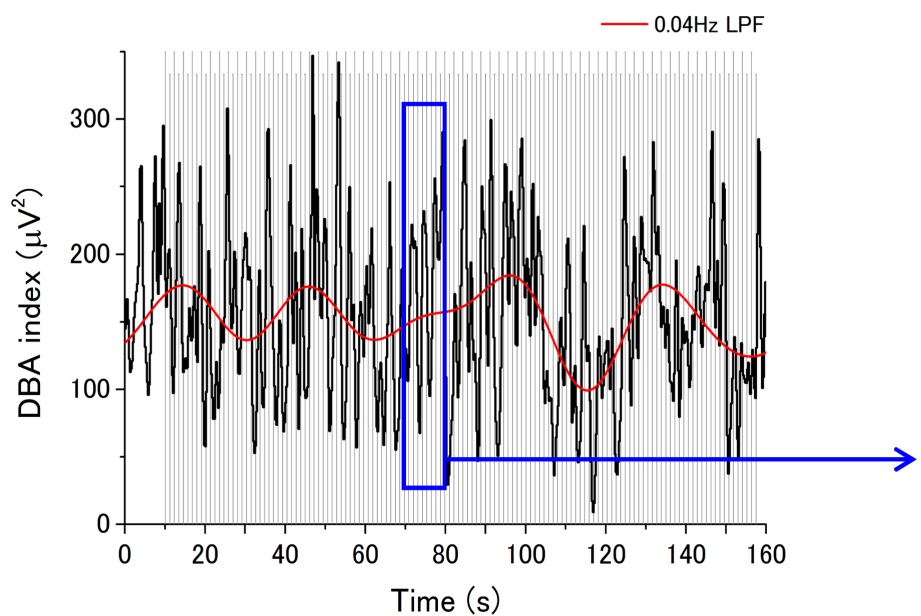

(a)

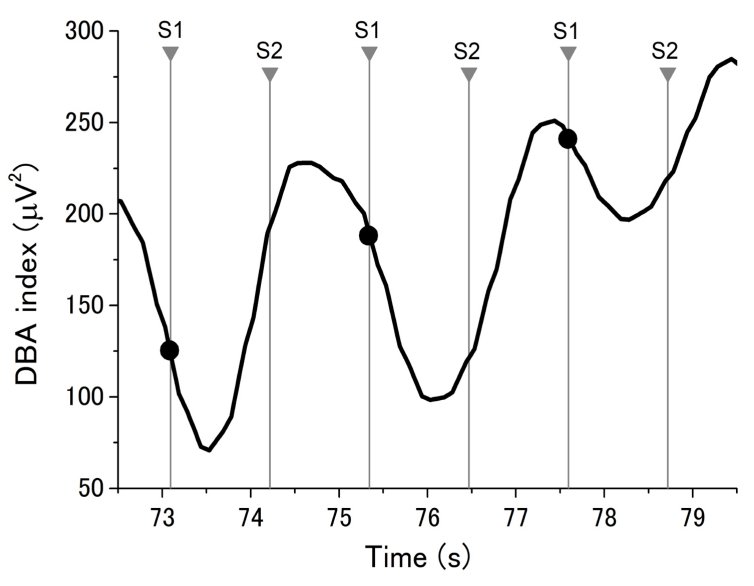

(b)

Figure 2. Two time series signals of deep brain activity (DBA) index. (a) The slow component of DBA index corresponding to the frequency of $0.04 \mathrm{~Hz}$; (b) The fast component of DBA index. Additional processing was performed with data extracted in a limited time range of approximately $2 \mathrm{~s}$ from the original DBA index data based on the onset markers of S1 as event markers, excluding outliers. The averaged temporal waveforms were defined as event-related (ER) DBA indices. Baseline correction was performed $200 \mathrm{~ms}$ prior to the onset of noun presentations (S1).

\subsection{Event-Related Potential Analysis}

Conventional event-related potential (ERP) measurement was performed with EEG signals at $\mathrm{Cz}$ for evaluating contingent negative variation (CNV) during tasks. The CNV, associated with the CEN during focusing of attention [52], is expected to support our claim based on the event-related DBA index analysis, which addresses roles of the dACC in cognitive processing.

\subsection{Statistical Analysis}

Statistical analysis of data was performed using the t-test to determine significant differences in error rate between NRT and VGT, and in ER-DBA indices among response types and groups. Statistical significance was primarily assessed by the $\mathrm{p}$ value $(p)$, which was confirmed by the power and Cohen's $\mathrm{d}$ value $(d)$. Total error incidence was further evaluated by measuring the interval of stimulus number between two consecutive errors. The measured interval data were statistically analyzed to determine probability density functions (PDFs) for the error incidence. PDFs were then used to examine whether committing the error affected post-error task performances.

\section{Results}

\subsection{Behavioral Performance Data}

We assessed the behavioral performance of subjects as CR, IR, or NR for each NRT and VGT trial, according to the criteria described in Materials and Methods. Table 2 lists the assessed results for all subjects. Error rates were significantly lower for NRT than for VGT $(p<0.001)$ (Figure 3$)$. 
Table 2. Behavioral performance data recorded for 12 subjects while performing noun repetition task (NRT) and verb generation task (VGT).

(a)

\begin{tabular}{|c|c|c|c|c|c|}
\hline \multirow{3}{*}{$\begin{array}{c}\text { Subject } \\
\text { ID }\end{array}$} & \multicolumn{5}{|c|}{ Noun repetition task (NRT) } \\
\hline & \multicolumn{3}{|c|}{$\operatorname{Response}^{\mathrm{a}}(\%)$} & \multicolumn{2}{|c|}{ Error trial $^{\mathrm{b}}$} \\
\hline & $\mathrm{CR}$ & IR & NR & IR & NR \\
\hline 1 & $58(96.7)$ & $0(0)$ & $2(3.3)$ & - & 2,27 \\
\hline 2 & $60(100)$ & $0(0)$ & $0(0)$ & - & - \\
\hline 3 & $57(95.0)$ & $3(5.0)$ & $0(0)$ & $29,37,47$ & - \\
\hline 4 & $55(91.7)$ & $5(8.3)$ & $0(0)$ & $2,3,21$ & - \\
\hline 5 & $58(96.7)$ & $2(3.3)$ & $0(0)$ & 1,2 & - \\
\hline 6 & $59(98.3)$ & $1(1.7)$ & $0(0)$ & 40 & - \\
\hline 7 & $59(98.3)$ & $1(1.7)$ & $0(0)$ & 1 & - \\
\hline 8 & $60(100)$ & $0(0)$ & $0(0)$ & - & - \\
\hline 9 & $59(98.3)$ & $1(1.67)$ & $0(0)$ & 47 & - \\
\hline 10 & $59(98.3)$ & $1(1.67)$ & $0(0)$ & 18 & - \\
\hline 11 & - & - & - & - & - \\
\hline 12 & $59(98.3)$ & $1(1.67)$ & $0(0)$ & 1 & - \\
\hline
\end{tabular}

(b)

\begin{tabular}{|c|c|c|c|c|c|}
\hline \multirow{3}{*}{$\begin{array}{l}\text { Subject } \\
\text { ID }\end{array}$} & & & & \multicolumn{2}{|c|}{ Verb generation task (VGT) } \\
\hline & \multicolumn{3}{|c|}{ Response $^{\mathrm{a}}(\%)$} & \multicolumn{2}{|c|}{ Error trial $^{\mathrm{b}}$} \\
\hline & CR & IR & NR & IR & NR \\
\hline 1 & $\begin{array}{c}44 \\
(73.3)\end{array}$ & $\begin{array}{c}1 \\
(1.7)\end{array}$ & $\begin{array}{c}15 \\
(25.0)\end{array}$ & 28 & $\begin{array}{c}5,7,12,14,17,19,20 \\
23,24,26,39,45,50,51,55\end{array}$ \\
\hline 2 & $\begin{array}{c}40 \\
(66.7)\end{array}$ & $\begin{array}{c}12 \\
(20.0)\end{array}$ & $\begin{array}{c}8 \\
(13.3)\end{array}$ & $\begin{array}{c}2,9,14,19,20,21 \\
32,33,44,48,50,57\end{array}$ & $1,24,36,38,39,51,53,60$ \\
\hline 3 & $\begin{array}{c}38 \\
(63.3)\end{array}$ & $\begin{array}{c}20 \\
(33.3)\end{array}$ & $\begin{array}{c}2 \\
(3.3)\end{array}$ & $\begin{array}{c}1,2,5,11-15,24,26,29,32 \\
33,36,39,47,51,55,59,60\end{array}$ & 16,17 \\
\hline 4 & $\begin{array}{c}40 \\
(66.7)\end{array}$ & $\begin{array}{c}5 \\
(8.3)\end{array}$ & $\begin{array}{c}15 \\
(25.0)\end{array}$ & $3,28-30,52$ & $\begin{array}{c}5,19,20,23,24,33,37 \\
39,44,45,47,55,56,58,60\end{array}$ \\
\hline 5 & $\begin{array}{c}43 \\
(71.7)\end{array}$ & $\begin{array}{c}13 \\
(21.7)\end{array}$ & $\begin{array}{c}4 \\
(6.7)\end{array}$ & $\begin{array}{c}1,20,24,27,28,30 \\
34,38,39,45,54,58,60\end{array}$ & $7,12,33,53$ \\
\hline 6 & $\begin{array}{c}50 \\
(83.3)\end{array}$ & $\begin{array}{c}3 \\
(5.0)\end{array}$ & $\begin{array}{c}7 \\
(11.7)\end{array}$ & $27,28,43$ & $24,33,36,39,45,51,60$ \\
\hline 7 & $\begin{array}{c}38 \\
(63.3)\end{array}$ & $\begin{array}{c}22 \\
(36.7)\end{array}$ & $\begin{array}{c}0 \\
(0)\end{array}$ & $\begin{array}{l}1,14,23,24,26-28,30,31,33,38 \\
40,43,45,47,48,53,55,56,58,60\end{array}$ & - \\
\hline 8 & $\begin{array}{c}45 \\
(75.0)\end{array}$ & $\begin{array}{c}15 \\
(25.0)\end{array}$ & $\begin{array}{c}0 \\
(0)\end{array}$ & $\begin{array}{c}14,17,20,24,25,30,32 \\
39,50,51,53,55,56,58,59\end{array}$ & - \\
\hline 9 & $\begin{array}{c}30 \\
(50.0)\end{array}$ & $\begin{array}{c}15 \\
(25.0)\end{array}$ & $\begin{array}{c}15 \\
(25.0)\end{array}$ & $\begin{array}{c}6,7,14,16,19,28,30 \\
32,33,37,40,51,52,58\end{array}$ & $\begin{array}{l}8,20,23,24,26,27,36 \\
39,44,45,53,55,59,60\end{array}$ \\
\hline 10 & $\begin{array}{c}36 \\
(60.0)\end{array}$ & $\begin{array}{c}20 \\
(33.3)\end{array}$ & $\begin{array}{c}4 \\
(6.7)\end{array}$ & $\begin{array}{c}9,15,19,22,24,26-30 \\
33,36-39,45,53,56,58,60\end{array}$ & $10,14,32,54$ \\
\hline 11 & $\begin{array}{c}46 \\
(76.7)\end{array}$ & $\begin{array}{c}6 \\
(10.0)\end{array}$ & $\begin{array}{c}8 \\
(13.3)\end{array}$ & $10,14,15,23,30,45$ & $19,24,31,36,38,39,51,53$ \\
\hline 12 & $\begin{array}{c}44 \\
(73.3)\end{array}$ & $\begin{array}{c}15 \\
(25.0)\end{array}$ & $\begin{array}{c}1 \\
(1.7)\end{array}$ & $\begin{array}{c}19,20,22-24,27-29 \\
32,33,39,44,58-60\end{array}$ & 14 \\
\hline
\end{tabular}

${ }^{a}$ Numbers indicated for each response represent the number of times that response was given by the subject out of a total of 60 trials. Numbers in paren-

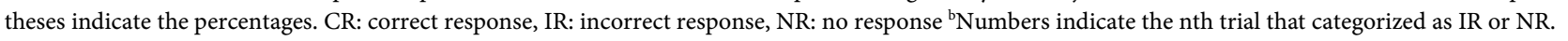




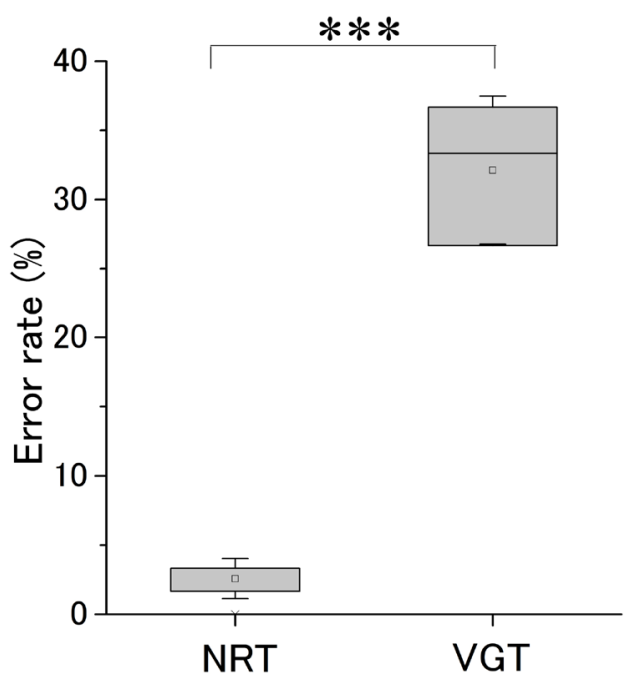

Figure 3. Comparison of total error rates for noun repetition task (NRT) and verb generation task (VGT). Error rates were significantly lower for NRT (Total error rate (\%): mean \pm SE: $2.3 \pm$ $0.8)$ than for VGT $(31.4 \pm 2.6)\left(\mathrm{n}=12,{ }^{* *}: p<\right.$ $0.001(p=6.8 \mathrm{e}-8), d=4.4)$. n, sample size; $d$, Cohen's d.

\subsection{Event-Related (ER) DBA Indices}

The ER-DBA index waveforms were derived from DBA index data of all subjects in a window of $2200 \mathrm{~ms}$ by arithmetic mean We found that the waveforms calculations. Waveforms exhibited performance differences (Figure 4(a)). The CR group showed a dip below the baseline just posterior to the onset of the auditory noun presentations (S1). The group also produced a mild increase several hundreds of ms prior to the arrival of the speech cues (S2). The IR group showed a sharp increase above the baseline accompanied with a negligible dip. By contrast, the NR group showed a steep dip spanning the entire time slot between the two auditory cuing signals of S1 and S2. We also calculated the ER-DBA waveforms for CR and IR groups of NRT (Figure 4(b)). A comparison between CR groups of NRT and VGT revealed significant differences $(p<0.001)$ with the dip for CR group of VGT being significantly deeper than that of NRT (Figure 4(c)).

\subsection{ERPs}

Calculations based on the conventional arithmetic mean paradigm were respectively done in the $\mathrm{Cz}$ deviations using data of all subjects for all behavioral groups (CR, IR, and NR) of VGT. The calculated ERP waveforms were represented in a time window of $2200 \mathrm{~ms}$ prior to the arrival of the auditory noun stimulus (S1) in 200-ms intervals (Figure 5(a)). The ERP waveform was characterized for all groups by sustained broad negativities. No significant differences were determined between these waveforms; however, the CR group enhanced the negativity compared with the other performance groups. The ERPs 


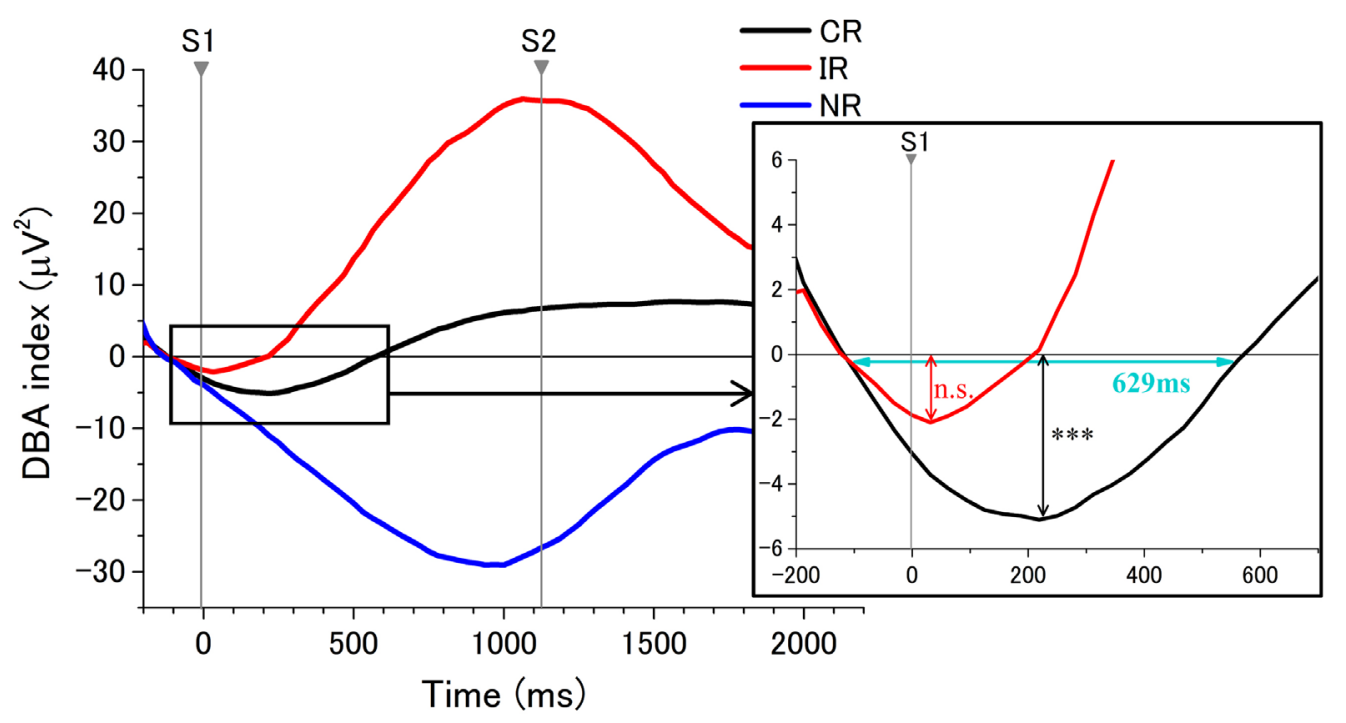

(a)

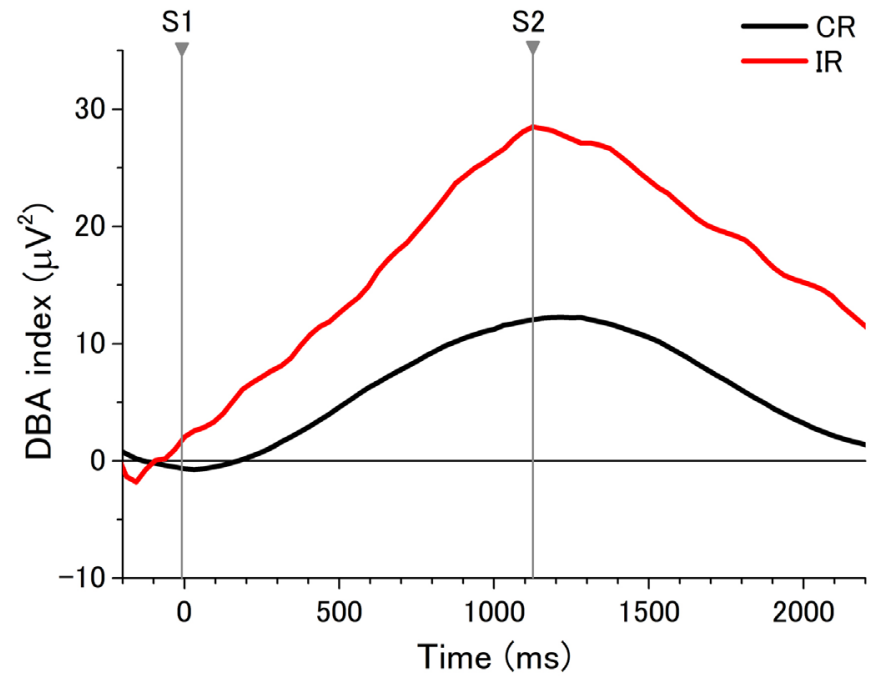

(b)

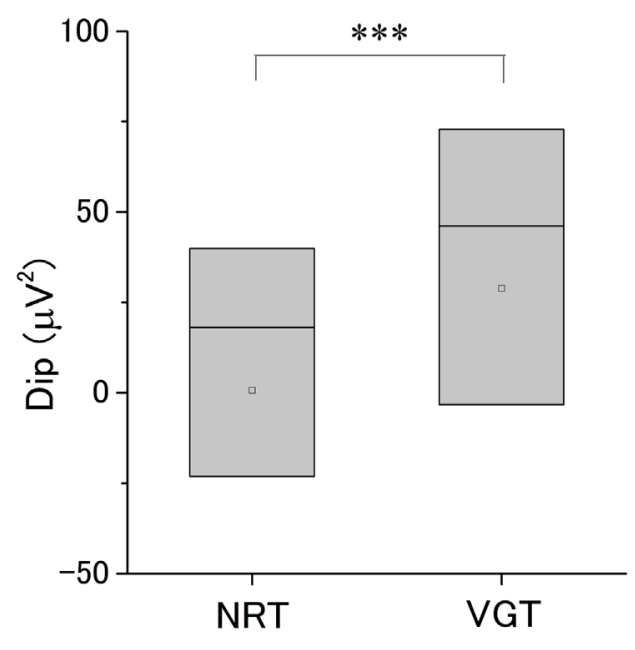

(c)

Figure 4. Event-related analyses on DBA index data. (a) CR $(\mathrm{n}=335)$, IR $(\mathrm{n}=101)$, and NR $(\mathrm{n}=51)$ data for VGT. The CR group showed a dip below the baseline [*** $p<0.001(p=1.9 \mathrm{e}-20)$, power $=1]$. The dip of the IR group was not significant $(p=0.42$, power = 0.13); (b) CR $(\mathrm{n}=554)$ and IR $(\mathrm{n}=15)$ data for NRT; (c) Comparison of DBA indices between CR groups of NRT and VGT [**: $p<0.001(p=1.2 \mathrm{e}-13), d=0.52]$. $\mathrm{n}$, sample size; $d$, Cohen's $\mathrm{d}$.

were also calculated in the same electrode deviations for the CR group of NRT (Figure 5(b)). Similar broad negativities were obtained following sustained negativities.

\subsection{Subtraction Analyses}

ER-DBA index and ERP waveforms. The CR group of NRT was used as a control for subtraction processing (Figure 6). The ER-DBA index waveform produced a broad sustained negativity covering the entire time range from the onset of the noun presentations (S1) to the arrival of the speech cues (S2), whereas the ERP 


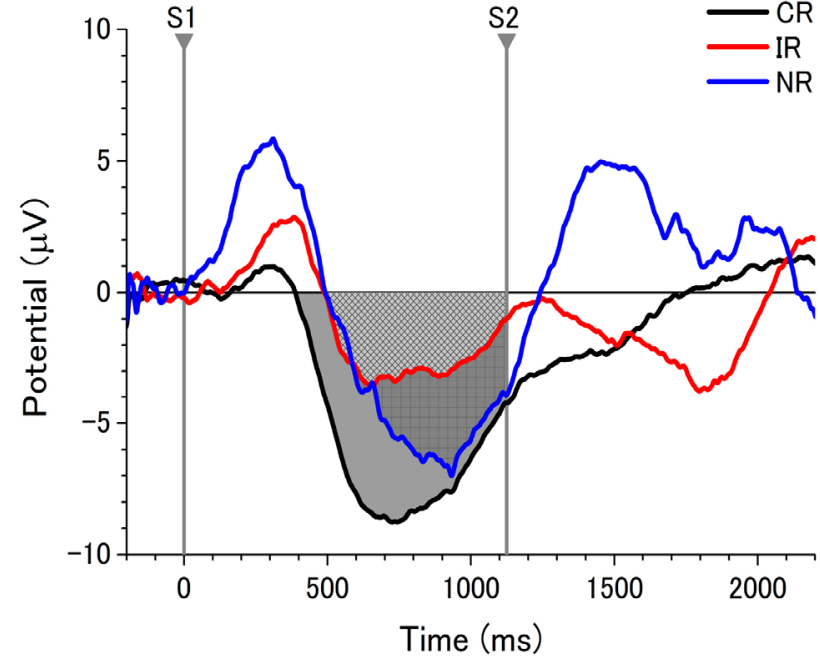

(a)

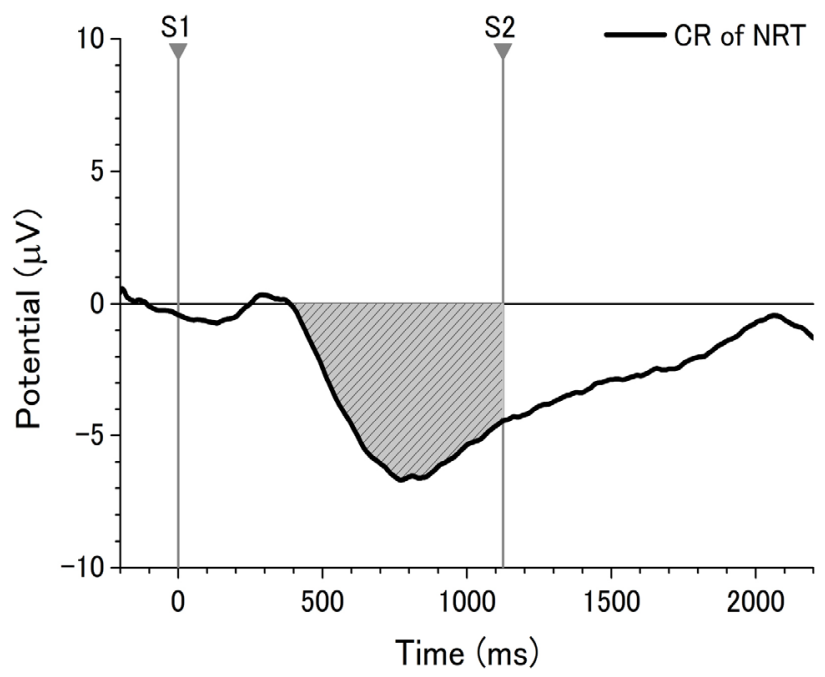

(b)

Figure 5. Event-related potential (ERP) waveforms. (a) ERP waveforms calculated for different three CR $(n=221)$, IR $(n=66)$, and NR $(n=35)$ behavioral groups of VGT; (b) ERP waveform calculated for the CR $(n=460)$ group of NRT. $n$, sample size.

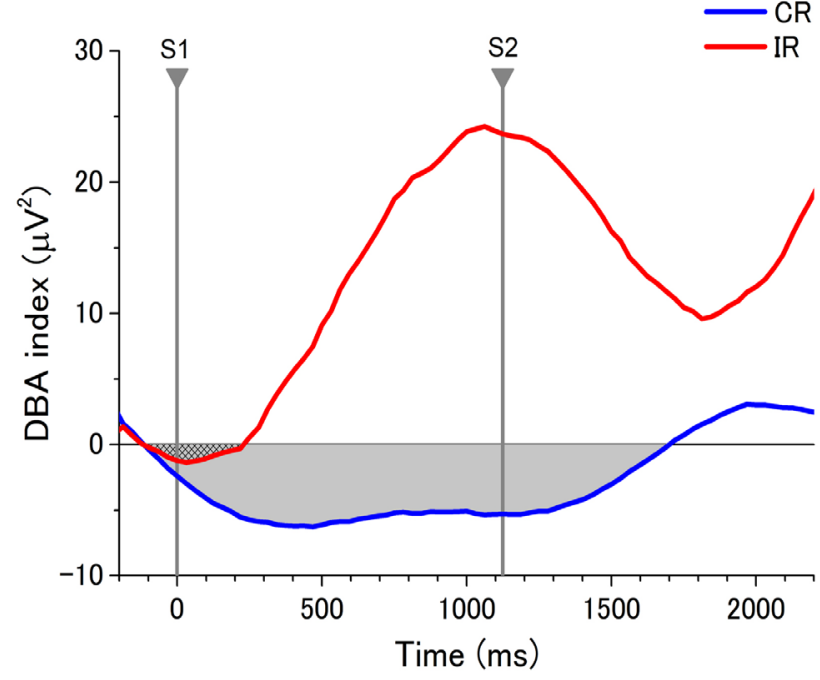

(a)

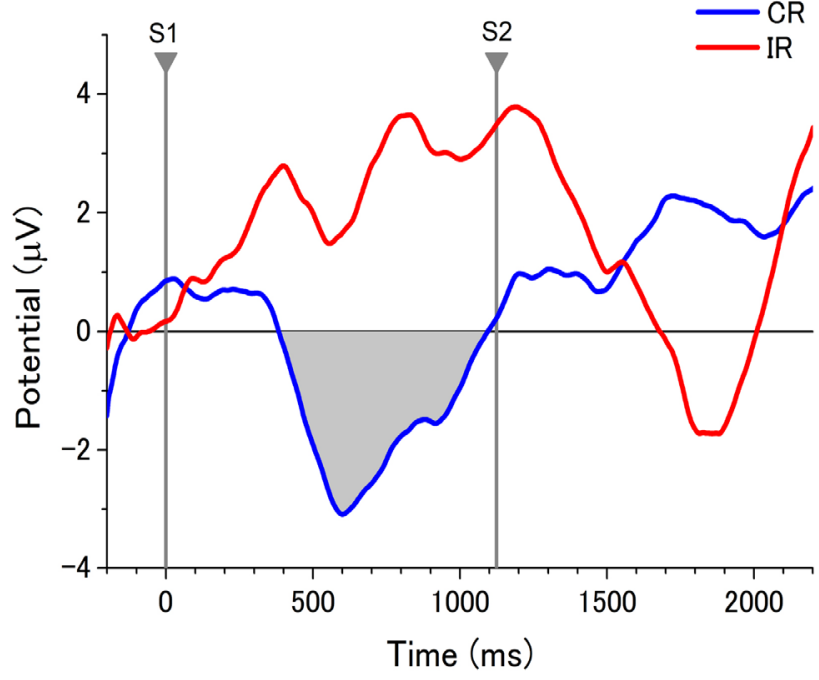

(b)

Figure 6. Conventional subtraction analysis for the ER-DBA index (a) and the ERP waveforms (b).

waveform showed negativity in a limited range between S1 and S2.

\subsection{Personal Differences}

We were especially interested in errors committed during VGT, because this task was associated with higher-order cognitive functions. Therefore, we investigated personal differences in behavioral performance based on the DBA index of each subject. The average DBA index showed a strong negative correlation with the total error rate including IR and NR groups, and a strong positive correlation with the dip depth of the ER-DBA index waveform of the CR group (Figure 7(b)). 


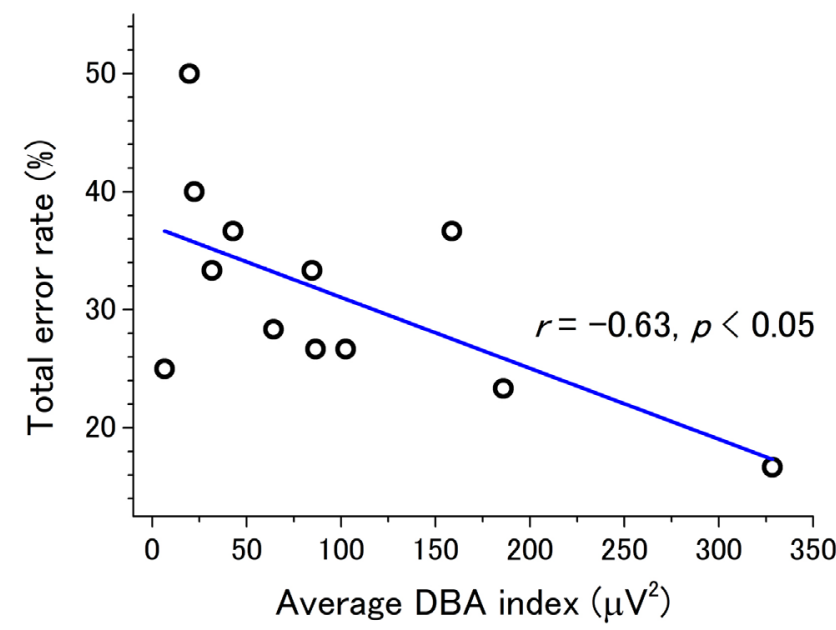

(a)

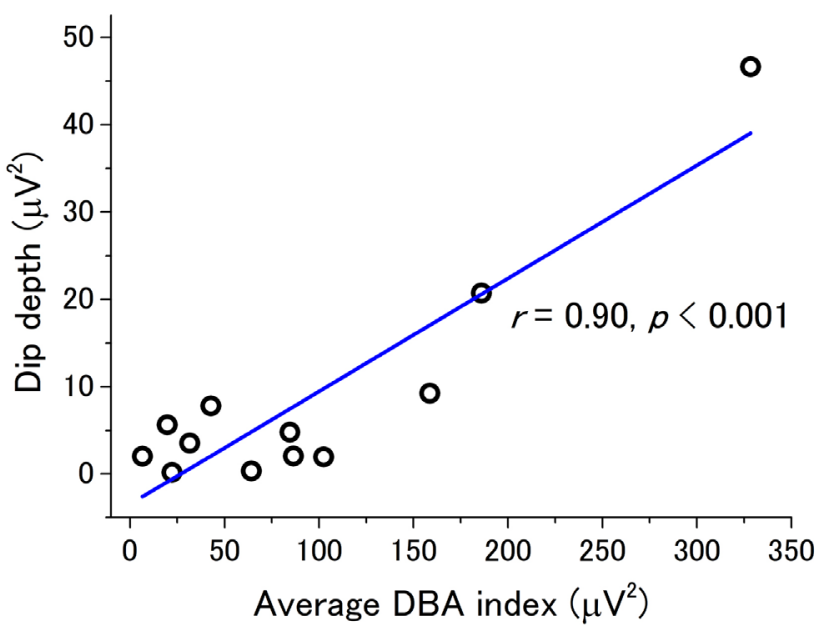

(b)

Figure 7. The average DBA index at rest versus (a) the total error rate and (b) the dip depth. The errors included both IR and NR. (a) $\mathrm{r}$ (Pearson's correlation coefficient) $=-0.63, p<0.05$ ( $p=0.03)$; (b) $r=0.90, p<0.001(p=5.2 \mathrm{e}-5)$.

\section{Discussion}

\subsection{Cognitive Processes Predicted by the Dip in ER-DBA Index Trace}

We found that ER-DBA index traces exhibited a dip immediately after the onset of the auditory word (noun) presentations for correct responses during the VGT (Figure 4(a)). As the fast component of DBA index reflects the dACC activity, the dip in ER-DBA indicates deactivation of dACC. The duration of the dip was approximately $600 \mathrm{~ms}$, which suggests that optimal verb retrieval was performed during the dip. The IPFC associated with the frontotemporal network is deactivated during semantic processing and word retrieving [53] [54]. A previous electrocorticogram (ECoG) study revealed that the PCC is also deactivated during semantic processing [55]. Together, these data suggest that dACC and IPFC are co-deactivated during optimal verb retrieval, further indicating that dACC is coupled with IPFC. This co-deactivation of dACC and IPFC is thought to originate from direct memory access with word processing under the speed-accuracy tradeoff condition for achieving the best task performance [56] [57].

It has also been shown that the DMN is coupled with task-positive networks, including the IPFC [19]. Hence, it is possible that the coupling between dACC and IPFC supports dACC-mediated deactivation of DMN during the verb retrieval task. Consequently, de-activation of large-scale brain networks, including $\mathrm{SN}$ and DMN, is thought to be essential for early-stage cognitive processing. On the other hand, such coupling increases the susceptibility of the subject to distraction by co-activation during tasks [58]. The risk is brought by excessive activation of the anterior insular cortex (aIC) responding to unpredictable stimuli [59] [60]. The IRs, given by the positive DBA index (Figure 4(a) and Figure 4(b)) corresponding to dACC activation, may be attributed to the dACC-activation-induced distraction. 
Correct response

Salient event
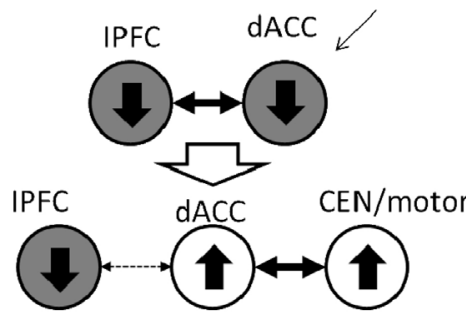

We also found that whether or not the verb retrieval was successful, the dACC exhibited subsequent increase in an interval of several hundred ms from the onset of word presentation. This increase corresponds to the behavior of the ACC when a solution is hit [43]. This suggests that dACC may couple with the CEN for performing goal-oriented processing, including decision-making and motor preparation for speech. This raises the question as to why such deactivation is needed for processing information. A possible explanation of the role of "deactivation" is attributed to the function of $\gamma$-aminobutyric acid (GABA) [61], which inhibits spontaneous neural spiking with no information [62] [63] or prohibits the incoming unnecessary impulses [64] [65] [66]. Such deactivation is beneficial for highlighting target information [67]. Figure 8 illustrates a schematic diagram for explaining dACC-oriented dynamic cognitive processing supported by the above findings.

\subsection{Temporal Dynamics Predicted by Subtraction Analyses}

We further found performance-specific DBA index and ERP traces from subtraction analyses data. Figure 9 shows a schematic diagram of cognitive processing predicted during NRT and VGT. By subtracting the common processes, we obtained the difference given by the additional processes of VGT, including verb retrieval and decision-making for selecting a verb suitable to the presented noun. The negativity of the subtracted DBA index difference over the time window from the onset of the word (noun) presentation to arrival of the speech cue (Figure 6(a)) is given by sustained attention for the VGT-specific cognitive processes as mentioned above. Such durable attention is consistent with the previous finding that the working-memory remains active during tasks while the DMN is deactivated [22].

On the other hand, the negativity of the subtracted ERP trace at $\mathrm{Cz}$ (Figure 6(b)), reflecting the readiness potential of the motor cortex [68] [69], emerged posterior to the dip bottom of the DBA index. The temporal discrepancy between the subtracted DBA index and ERP traces indicates that the word processing and motor preparation are dissociable. This dissociation is attributed to the salience function of AACC, which regulates the motor system by immediately breaking off the coupling with the IPFC for engaging the cued speech.

Incorrect response

No response

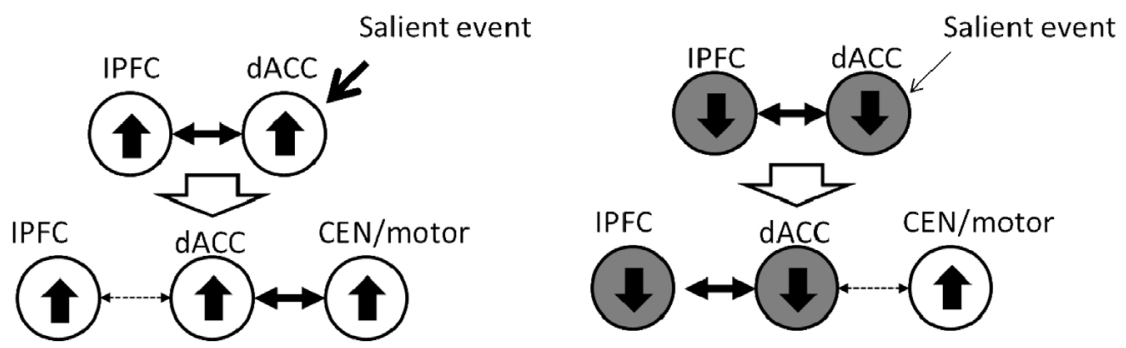

Figure 8. Schematic representation of performance-dependent dynamic interactions between dACC, IPFC, and CEN/motor system during cognitive processing. 


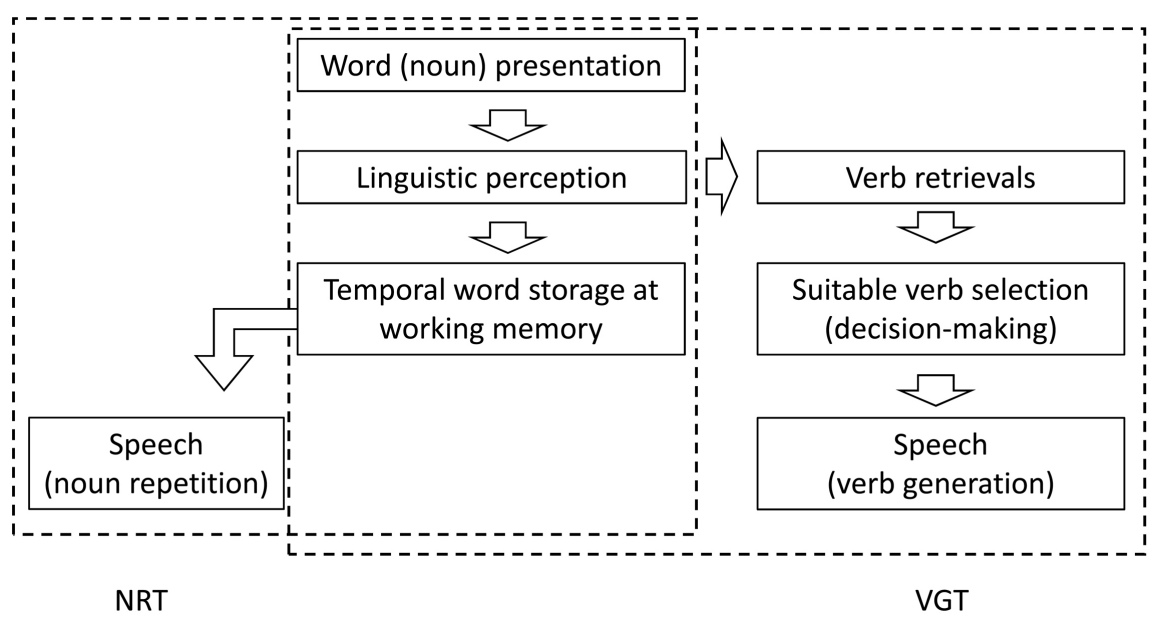

Figure 9. A schematic diagram of cognitive processing predicted during the two tasks of NRT and VGT.

The flexible intra-coupling aspects of AACC with altered coupling states between the default and executive networks are essential for its salience function [70]. This flexibility supports the reconfigurable human brain networks for engaging a wide variety of cognitive demands [71] [72]. Our results are the first evidence for such network architectures.

\subsection{Personal Differences}

Deep brain structures are characterized by monoaminergic neural systems, especially the dopaminergic system at the ventral tegmental area (VTA) involved in the upper brainstem. This neural system is not only essential for reward [73], but also improves connectivity of large-scale networks of the human brain [74] [75] [76]. By contrast, according to small-scale network architectures [77] [78], network connectivity is dependent on the modularity of neural systems. As the number of impulses pending processing increase at the synapse with decreasing the modularity, the network connectivity is improved at the cost of metabolic stress [77] [79]. Hence, connectivity and metabolic cost are counterbalanced.

In this study, we found that the dip depth of ER-DBA index traces was positively correlated with the slow component of the DBA index (Figure 7(b)), i.e., the activity of the dopaminergic neural system at the VTA. This suggests that those who possess higher dopaminergic neural activity at rest can improve their brain network connectivity for achieving best performance during tasks against higher metabolic cost. Assuming that task performance is correlated with network connectivity, performance and metabolic cost are also counterbalanced. Hence, personal differences of cognitive behaviors are determined according to the cost of each task [80].

\subsection{Error Incidence}

It is known that sustained influence of errors commission is avoided by post error slowing (PES), supported by brain activation [81]. Taking into account that 
performance accuracy is affected by emotional stimuli or internal motivation [82] [83], we hypothesized that the dynamic performance of the dACC promotes the brain activation associated with PES.

When post-error influence is avoided by PES, there is no correlation in error commission. Hence, if the random error incidence is confirmed in our experimental results, it will be appreciated that the dACC will contribute to maintaining performance accuracy during tasks.

To examine this hypothesis, we statistically analyzed error intervals, derived from the number of errors listed in Table 2. The PDFs determined for most of the subjects exhibited good correspondence $(p<0.05)$ with exponential distribution derived from Erlang distribution,

$$
p(n)=\frac{\lambda(\lambda n)^{\kappa-1}}{(n-1) !} \exp (-\lambda n)
$$

where $\kappa=1$ for exponential distribution (Figure 10). The exponential PDF is derived from random stochastic processes as observed in the natural science fields addressing, for example, a many-body problem in quantum physics [84]. Hence, the random error incidence as shown in Figure 10(a) is evidential to our hypothesis.

Indeed, some subjects provided exceptional performance depicting non-exponential PDF, which was rather approximated with a higher-order $(\kappa>$ 1) Erlang distribution function (Figure 10(b)). It was considered that such higher order Erlang distribution was attributed to excessive activation of the dACC, which would intensively suppress successive error commission. Hence, such exceptions still support our claim, although they are not associated with

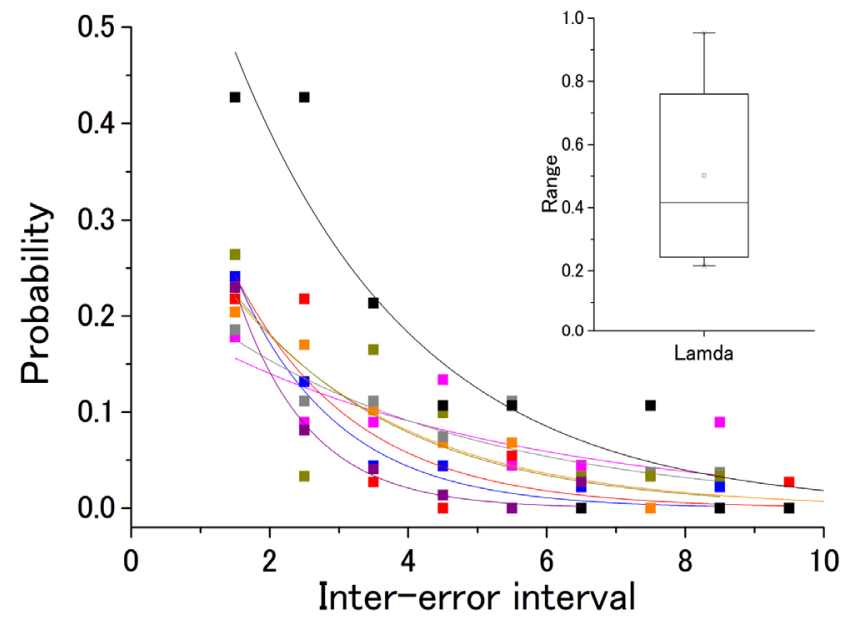

(a)

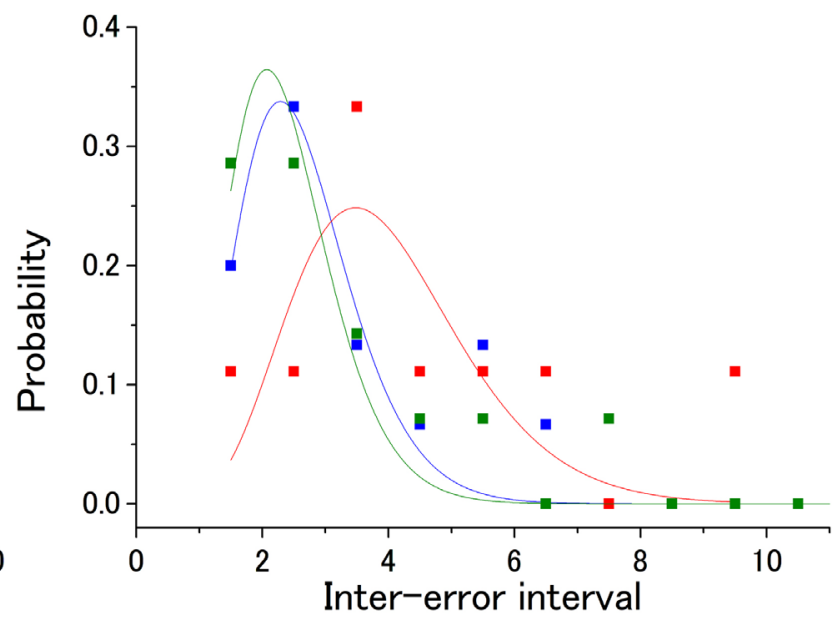

(b)

Figure 10. Probability density functions (PDFs) of error intervals across subjects. Solid lines indicate individual data. (a) $72 \%$ of the subjects provided PDFs fitted with the exponential distribution $(p<0.05)$, corresponding to $\kappa=1$ in the Erlang distribution, $p(n)=\frac{\lambda(\lambda n)^{\kappa-1}}{(n-1) !} \exp (-\lambda n)$; (b) $20 \%$ of the subjects produced exceptional examples deviant from the exponential distribution, best fitted with $\kappa=8$ of the Erlang distribution under statistical significance $(p<0.001)$. 
random stochastic processes.

\subsection{Limitations}

This study has a few limitations. First, the study was limited to healthy subjects. Future studies should apply the novel event-related DBA index method to assess symptoms of patients with cognitive dysfunctions in clinical fields. Second, the study was limited to word-based paradigms because our primary goal is to understand cognitive processing during word retrieval. Therefore, future studies should examine the method for investigating more general cognition schemes typically including visual processing.

\section{Conclusions}

We investigated the dynamic behavior of dACC during word generation tasks using a newly developed ER-DBA index for elucidating mechanisms underlying $\mathrm{SN}$-dominant cognitive processing. We found remarkable performance-dependent ER-DBA traces accompanied with a dip in DBA corresponding to subsequent dACC deactivation after word presentation. We also found personal dependence, according to which the DBA dip becomes stronger for those who exhibit higher average DBA index at rest. These findings suggest that the AACC is deactivated during cognitive processing from predicted task-negative regions, including the IPFC, but is activated during the execution stage with task-positive regions, including the $\mathrm{CEN}$ and motor system. Data also suggested that such dACC function in cognitive processing is supported by the monoaminergic neural systems at the upper brainstem region.

Future studies will be conducted to understand neural mechanisms underlying performance-based difference reflected in ER-DBA traces during cognitive tasks and those involved in cognitive impairment observed in various diseases. Hence, characterization of ER-DBA traces during cognitive tasks will be highly valuable for providing precise diagnosis of a wide range of diseases with cognitive impairment in clinical settings.

\section{Acknowledgements}

This study was partially supported by JSPS KAKENHI Grant Number JP16K01307.

\section{References}

[1] Clark, D.B., Chung, T., Martin, C.S., Hasler, B.P., Fitzgerald, D.H., Luna, B., Brown, S.A., Tapert, S.F., Brumback, T., Cummins, K., Pfefferbaum, A., Sullivan, E.V., Pohl, K.M., Colrain, I.M., Baker, F.C., De Bellis, M.D., Nooner, K.B. and Nagel, B.J. (2017) Adolescent Executive Dysfunction in Daily Life: Relationships to Risks, Brain Structure and Substance Use. Frontiers in Behavioral Neuroscience, 11, 223. http://dx.doi.org/10.3389/fnbeh.2017.00223

[2] Lee Mortensen, G. and Rasmussen, P.V. (2017) The Impact of Quality of Life on Treatment Preferences in Multiple Sclerosis Patients. Patient Prefer Adherence, 11, 
1789-1796. http://dx.doi.org/10.2147/PPA.S142373

[3] Stites, S.D., Karlawish, J., Harkins, K., Rubright, J.D. and Wolk, D. (2017) Awareness of Mild Cognitive Impairment and Mild Alzheimer's Disease Dementia Diagnoses Associated With Lower Self-Ratings of Quality of Life in Older Adults. Journals of Gerontology Series B: Psychological Sciences and Social Sciences, 72, 974-985. http://dx.doi.org/10.1093/geronb/gbx100

[4] Storch, E.A., Small, B.J., McGuire, J.F., Murphy, T.K., Wilhelm, S. and Geller, D.A. (2017) Quality of Life in Children and Youth with Obsessive-Compulsive Disorder. Journal of Child and Adolescent Psychopharmacology, [Epub Ahead of Print].

[5] Silverberg, N.D., Wojtowicz, M., Bui, E., Wershba, R., Zafonte, R., Laifer, L.M., Simon, N.M. and Iverson, G.L. (2017) Contribution of Perceived Cognitive Functioning to Quality of Life in Service Members and Veterans With Posttraumatic Stress Disorder. Journal of Traumatic Stress, 30, 318-322.

http://dx.doi.org/10.1002/jts.22184

[6] Vlagsma, T.T., Koerts, J., Tucha, O., Dijkstra, H.T., Duits, A.A., van Laar, T. and Spikman, J.M. (2017) Objective versus Subjective Measures of Executive Functions: Predictors of Participation and Quality of Life in Parkinson Disease? Archives of Physical Medicine and Rehabilitation, 98, 2181-2187.

http://dx.doi.org/10.1016/j.apmr.2017.03.016

[7] Ertem, D.H., Dirican, A.C., Aydın, A., Baybas, S., Sözmen, V., Ozturk, M. and Altunkaynak, Y. (2017) Exploring Psychiatric Comorbidities and Their Effects on Quality of Life in Patients with Temporal Lobe Epilepsy and Juvenile Myoclonic Epilepsy. Psychiatry and Clinical Neurosciences, 71, 280-288. https://doi.org/10.1111/pcn.12499

[8] Ghazavi, Z., Rahimi, E., Yazdani, M. and Afshar, H. (2016) Effect of Cognitive Behavioral Stress Management Program on Psychosomatic Patients' Quality of Life. Iranian Journal of Nursing and Midwifery Research, 21, 510-515. http://dx.doi.org/10.4103/1735-9066.193415

[9] Mohan, A., Roberto, A.J., Mohan, A., Lorenzo, A., Jones, K., Carney, M.J., Liogier-Weyback, L., Hwang, S. and Lapidus, K.A. (2016) The Significance of the Default Mode Network (DMN) in Neurological and Neuropsychiatric Disorders: A Review. Yale Journal of Biology and Medicine, 89, 49-57.

[10] Costafreda, S.G., Fu, C.H., Picchioni, M., Toulopoulou, T., McDonald, C., Kravariti, E., Walshe, M., Prata, D., Murray, R.M. and McGuire, P.K. (2011) Pattern of Neural Responses to Verbal Fluency Shows Diagnostic Specificity for Schizophrenia and Bipolar Disorder. BMC Psychiatry, 11, 18. http://dx.doi.org/10.1186/1471-244X-11-18

[11] Silberstein, R.B., Pipingas, A., Farrow, M., Levy, F. and Stough, C.K. (2016) Dopaminergic Modulation of Default Mode Network Brain Functional Connectivity in Attention Deficit Hyperactivity Disorder. Brain and Behavior, 6, e00582. http://dx.doi.org/10.1002/brb3.582

[12] Kucyi, A., Hove, M.J., Biederman, J., Van Dijk, K.R. and Valera, E.M. (2015) Disrupted Functional Connectivity of Cerebellar Default Network Areas in Attention-Deficit/Hyperactivity Disorder. Human Brain Mapping, 36, 3373-3386. http://dx.doi.org/10.1002/hbm.22850

[13] Ypma, R.J., Moseley, R.L., Holt, R.J., Rughooputh, N., Floris, D.L., Chura, L.R., Spencer, M.D., Baron-Cohen, S., Suckling, J., Bullmore, E.T. and Rubinov, M. (2016) Default Mode Hypoconnectivity Underlies a Sex-Related Autism Spectrum. Biological Psychiatry: Cognitive Neuroscience and Neuroimaging, 1, 364-371. http://dx.doi.org/10.1016/j.bpsc.2016.04.006 
[14] McFadden, K.L., Tregellas, J.R., Shott, M.E. and Frank, G.K. (2014) Reduced Salience and Default Mode Network Activity in Women with Anorexia Nervosa. Journal of Psychiatry \& Neuroscience, 39, 178-188. https://doi.org/10.1503/jpn.130046

[15] Geng, H., Li, X., Chen, J., Li, X. and Gu, R. (2016) Decreased Intra- and Inter-Salience Network Functional Connectivity is Related to Trait Anxiety in Adolescents. Frontiers in Behavioral Neuroscience, 9, 350. http://dx.doi.org/10.3389/fnbeh.2015.00350

[16] Zhou, Y., Liang, M., Tian, L., Wang, K., Hao, Y., Liu, H., Liu, Z. and Jiang, T. (2007) Functional Disintegration in Paranoid Schizophrenia Using Resting-State fMRI. Schizophrenia Research, 97, 194-205. http://dx.doi.org/10.1016/j.schres.2007.05.029

[17] Buckner, R.L., Snyder, A.Z., Shannon, B.J., LaRossa, G., Sachs, R., Fotenos, A.F., Sheline, Y.I., Klunk, W.E., Mathis, C.A., Morris, J.C. and Mintun, M.A. (2005) Molecular, Structural, and Functional Characterization of Alzheimer's Disease: Evidence for a Relationship between Default Activity, Amyloid, and Memory. Journal of Neuroscience, 25, 7709-7717.

http://dx.doi.org/10.1523/JNEUROSCI.2177-05.2005

[18] Greicius, M.D., Srivastava, G., Reiss, A.L. and Menon, V. (2004) Default-Mode Network Activity Distinguishes Alzheimer's Disease from Healthy Aging: Evidence from Functional MRI. Proceedings of the National Academy of Sciences of the United States of America, 101, 4637-4642. http://dx.doi.org/10.1073/pnas.0308627101

[19] Elton, A. and Gao, W. (2015) Task-Positive Functional Connectivity of the Default Mode Network Transcends Task Domain. Journal of Cognitive Neuroscience, 27, 2369-2381. https://doi.org/10.1162/jocn_a_00859

[20] Zhang, K., Ma, J., Lei, D., Wang, M., Zhang, J. and Du, X. (2015) Task Positive and Default Mode Networks during a Working Memory in Children with Primary Monosymptomatic Nocturnal enuresis and Healthy Controls. Pediatric Research, 78, 422-429. http://dx.doi.org/10.1038/pr.2015.120

[21] Haatveit, B., Jensen, J., Alnæs, D., Kaufmann, T., Brandt, C.L., Thoresen, C., Andreassen, O.A., Melle, I., Ueland, T. and Westlye, L.T. (2016) Reduced Load-Dependent Default Mode Network Deactivation across Executive Tasks in Schizophrenia Spectrum Disorders. NeuroImage: Clinical, 12, 389-396. http://dx.doi.org/10.1016/j.nicl.2016.08.012

[22] Koshino, H., Minamoto, T., Ikeda, T., Osaka, M., Otsuka, Y. and Osaka, N. (2011) Anterior Medial Prefrontal Cortex Exhibits Activation during Task Preparation but Deactivation during Task Execution. PLoS ONE, 6, e22909. http://dx.doi.org/10.1371/journal.pone.0022909

[23] Piccoli, T., Valente, G., Linden, D.E., Re, M., Esposito, F., Sack, A.T. and Di Salle, F. (2015) The Default Mode Network and the Working Memory Network Are Not Anti-Correlated during All Phases of a Working Memory Task. PLOS ONE, 10, e0123354. http://dx.doi.org/10.1371/journal.pone.0123354

[24] Čeko, M., Gracely, J.L., Fitzcharles, M.A., Seminowicz, D.A., Schweinhardt, P. and Bushnell, M.C. (2015) Is a Responsive Default Mode Network Required for Successful Working Memory Task Performance? Journal of Neuroscience, 35, 11595-11605. https://doi.org/10.1523/JNEUROSCI.0264-15.2015

[25] Koshino, H., Minamoto, T., Yaoi, K., Osaka, M. and Osaka, N. (2014) Coactivation of the Default Mode Network Regions and Working Memory Network Regions during Task Preparation. Scientific Reports, 4, Article Number: 5954. 
http://dx.doi.org/10.1038/srep05954

[26] Uddin, L.Q., Kelly, A.M., Biswal, B.B., Castellanos, F.X. and Milham, M.P. (2009) Functional Connectivity of Default Mode Network Components: Correlation, Anticorrelation, and Causality. Human Brain Mapping, 30, 625-637.

http://dx.doi.org/10.1002/hbm.20531

[27] Fox, M.D., Snyder, A.Z., Vincent, J.L., Corbetta, M., Van Essen, D.C. and Raichle, M.E. (2005) The Human Brain Is Intrinsically Organized into Dynamic, Anticorrelated Functional Networks. Proceedings of the National Academy of Sciences of the United States of America, 102, 9673-9678. http://dx.doi.org/10.1073/pnas.0504136102

[28] Di, X. and Biswal, B.B. (2014) Modulatory Interactions between the Default Mode Network and Task Positive Networks in Resting-State. PeerJ, 2, e367. http://dx.doi.org/10.7717/peerj.367

[29] Mijalkov, M., Kakaei, E., Pereira, J.B., Westman, E. and Volpe, G. (2017) BRAPH: A graph Theory Software for the Analysis of Brain Connectivity. PLoS ONE, 12, e0178798. http://dx.doi.org/10.1371/journal.pone.0178798

[30] Milano, M., Guzzi, P.H., Tymofieva, O., Xu, D., Hess, C., Veltri, P. and Cannataro, M. (2017) An Extensive Assessment of Network Alignment Algorithms for Comparison of Brain Connectomes. BMC Bioinformatics, 18, 235. http://dx.doi.org/10.1186/s12859-017-1635-7

[31] Cole, M.W., Bassett, D.S., Power, J.D., Braver, T.S. and Petersen, S.E. (2014) Intrinsic and Task-Evoked Network Architectures of the Human Brain. Neuron, 83, 238-251. http://dx.doi.org/10.1016/j.neuron.2014.05.014

[32] Gong, D., He, H., Ma, W., Liu, D., Huang, M., Dong, L., Gong, J., Li, J., Luo, C. and Yao, D. (2016) Functional Integration between Salience and Central Executive Networks: A Role for Action Video Game Experience. Neural Plasticity, 2016, Article ID: 9803165. http://dx.doi.org/10.1155/2016/9803165

[33] Uddin, L.Q., Supekar, K.S., Ryali, S. and Menon, V. (2011) Dynamic Reconfiguration of Structural and Functional Connectivity across Core Neurocognitive Brain Networks with Development. Journal of Neuroscience, 31, 18578-18589. http://dx.doi.org/10.1523/JNEUROSCI.4465-11.2011

[34] Seeley, W.W., Menon, V., Schatzberg, A.F., Keller, J., Glover, G.H., Kenna, H., Reiss, A.L. and Greicius, M.D. (2007) Dissociable Intrinsic Connectivity Networks for Salience Processing and Executive Control. Journal of Neuroscience, 27, 2349-2356. http://dx.doi.org/10.1523/JNEUROSCI.5587-06.2007

[35] Elton, A. and Gao, W. (2014) Divergent Task-Dependent Functional Connectivity of Executive Control and Salience Networks, Cortex, 51, 56-66. http://dx.doi.org/10.1016/j.cortex.2013.10.012

[36] Huijbers, W., Pennartz, C.M., Cabeza, R. and Daselaar, S.M. (2011) The Hippocampus Is Coupled with the Default Network during Memory Retrieval But Not during Memory Encoding. PLoS ONE, 6, e17463. http://dx.doi.org/10.1371/journal.pone.0017463

[37] Huettel, S.A. (2012) Event-Related fMRI in Cognition. NeuroImage, 62, 1152-1156. http://dx.doi.org/10.1016/j.neuroimage.2011.08.113

[38] Liu, T.T. (2012) The Development of Event-Related fMRI Designs. NeuroImage, 62, 1157-1162. http://dx.doi.org/10.1016/j.neuroimage.2011.10.008

[39] Bentley, W.J., Li, J.M., Snyder, A.Z., Raichle, M.E. and Snyder, L.H. (2016) Oxygen Level and LFP in Task-Positive and Task-Negative Areas: Bridging BOLD fMRI and Electrophysiology. Cerebral Cortex, 26, 346-357. 
http://dx.doi.org/10.1093/cercor/bhu260

[40] Petersen, S.E., Fox, P.T., Posner, M.I., Mintun, M. and Raichle, M.E. (1988) Positron Emission Tomographic Studies of the Cortical Anatomy of Single-Word Processing. Nature, 331, 585-589. http://dx.doi.org/10.1038/331585a0

[41] Fiez, J.A., Raichle, M.E., Balota, D.A., Tallal, P. and Petersen, S.E. (1966) PET Activation of Posterior Temporal Regions during Auditory Word Presentation and Verb Generation. Cerebral Cortex, 6, 1-10. https://doi.org/10.1093/cercor/6.1.1

[42] Liotti, M., Gay, C.T. and Fox, P.T. (1994) Functional Imaging and Language: Evidence from Positron Emission Tomography. Journal of Clinical Neurophysiology, 11, 175-190. https://doi.org/10.1097/00004691-199403000-00003

[43] Anderson, J.R., Anderson, J.F., Ferris, J.L., Fincham, J.M. and Jung, K.J. (2009) Lateral Inferior Prefrontal Cortex and Anterior Cingulate Cortex Are Engaged at Different Stages in the Solution of Insight Problems. Proceedings of the National Academy of Sciences of the United States of America, 106, 10799-10804. http://dx.doi.org/10.1073/pnas.0903953106

[44] Sadato, N., Nakamura, S., Oohashi, T., Nishina, E., Fuwamoto, Y., Waki, A. and Yonekura, Y. (1998) Neural Networks for Generation and Suppression of Alpha Rhythm: A PET Study. NeuroReport, 30, 893-897. http://dx.doi.org/10.1097/00001756-199803300-00024

[45] Goldman, R.I., Stern, J.M., Engel Jr., J. and Cohen. M.S. (2002) Simultaneous EEG and fMRI of the Alpha Rhythm. NeuroReport, 13, 2487-2492. http://dx.doi.org/10.1097/00001756-200212200-00022

[46] Schreckenberger, M., Lange-Asschenfeldt, C., Lochmann, M., Mann, K., Siessmeier, T., Buchholz, H.G., Bartenstein, P. and Gründer, G. (2004) The Thalamus as the Generator and Modulator of EEG Alpha Rhythm: A Combined PET/EEG Study with Lorazepam Challenge in Humans. NeuroImage, 22, 637-644. http://dx.doi.org/10.1016/j.neuroimage.2004.01.047

[47] Larson, C.L., Davidson, R.J., Abercrombie, H.C., Ward, R.T., Schaefer, S.M., Jackson, D.C., Holden, J.E. and Perlman, S.B. (1998) Relations between PET-Derived Measures of Thalamic Glucose Metabolism and EEG Alpha Power. Psychophysiology, 35, 162-169. https://doi.org/10.1111/1469-8986.3520162

[48] Omata, K., Hanakawa, T., Morimoto, M. and Honda, M. (2013) Spontaneous Slow Fluctuation of EEG Alpha Rhythm Reflects Activity in Deep-Brain Structures: A Simultaneous EEG-fMRI Study. PLoS ONE, 8, e66869. http://dx.doi.org/10.1371/journal.pone.0066869

[49] Huang, W., Zhang, W. and Li, F. (2015) Swept Optical SSB-SC Modulation Technique for High-Resolution Large-Dynamic-Range Static Strain Measurement Using FBG-FP Sensors. Optics Letters, 40, 1406-1409.

http://dx.doi.org/10.1364/OL.40.001406

[50] Loizides, C., Achilleos, A., Iannetti, G.D. and Mitsis, G.D. (2014) A Mixed Effects Model Framework for the Assessment of Nonlinear Interactions in Event-Related Potentials (ERPs) Elicited by Identical Successive Stimuli. The 36th Annual International Conference of the IEEE Engineering in Medicine and Biology Society, Chicago, IL, 26-30 August 2014, 4543-4546. http://dx.doi.org/10.1109/EMBC.2014.6944634

[51] Jasinski, E.C. and Coch, D. (2012) ERPs across Arithmetic Operations in a Delayed Answer Verification Task. Psychophysiology, 49, 943-958. http://dx.doi.org/10.1111/j.1469-8986.2012.01378.x

[52] Mannarelli, D., Pauletti, C., Grippo, A., Amantini, A., Augugliaro, V., Currà, A., 
Missori, P., Locuratolo, N., De Lucia, M.C., Rinalduzzi, S. and Fattapposta, F. (2015) The Role of the Right Dorsolateral Prefrontal Cortex in Phasic Alertness: Evidence from a Contingent Negative Variation and Repetitive Transcranial Magnetic Stimulation Study. Neural Plasticity, 2015, Article ID: 410785. http://dx.doi.org/10.1155/2015/410785

[53] Seghier, M.L. and Price, C.J. (2012) Functional Heterogeneity within the Default Network during Semantic Processing and Speech Production. Frontiers in Psychology, 3, 281. http://dx.doi.org/10.3389/fpsyg.2012.00281

[54] Hartwigsen, G., Henseler, I., Stockert, A., Wawrzyniak, M., Wendt, C., Klingbeil, J., Baumgaertner, A. and Saur, D. (2017) Integration Demands Modulate Effective Connectivity in a Frontotemporal Network for Contextual Sentence Integration. NeuroImage, 147, 812-824. http://dx.doi.org/10.1016/j.neuroimage.2016.08.026

[55] Jerbi, K., Vidal, J.R., Ossandon, T., Dalal, S.S., Jung, J., Hoffmann, D., Minotti, L., Bertrand, O., Kahane, P. and Lachaux, J.P. (2010) Exploring the Electrophysiological Correlates of the Default-Mode Network with Intracerebral EEG. Frontiers in Systems Neuroscience, 4, 27. http://dx.doi.org/10.3389/fnsys.2010.00027

[56] Foraker, S. and McElree, B. (2011) Comprehension of Linguistic Dependencies: Speed-Accuracy Tradeoff Evidence for Direct-Access Retrieval from Memory. Language and Linguistics Compass, 5, 764-783. http://dx.doi.org/10.1111/j.1749-818X.2011.00313.x

[57] Mizrak, E. and Öztekin, I. (2016) Working Memory Capacity and Controlled Serial Memory Search. Cognition, 153, 52-62. http://dx.doi.org/10.1016/j.cognition.2016.04.007

[58] Götting, F.N., Borchardt, V., Demenescu, L.R., Teckentrup, V., Dinica, K., Lord, A.R., Rohe, T., Hausdörfer, D., Li, M., Metzger, C.D. and Walter, M. (2017) Higher Interference Susceptibility in Reaction Time Task Is Accompanied by Weakened Functional Dissociation between Salience and Default Mode Network. Neuroscience Letters, 649, 34-40. http://dx.doi.org/10.1016/j.neulet.2017.03.035

[59] Gorka, S.M., Nelson, B.D., Phan, K.L. and Shankman, S.A. (2014) Insula Response to Unpredictable and Predictable Aversiveness in Individuals with Panic Disorder and Comorbid Depression. Biology of Mood \& Anxiety Disorders, 4, 9. http://dx.doi.org/10.1186/2045-5380-4-9

[60] Kalisch, R. and Gerlicher, A.M. (2014) Making a Mountain out of a Molehill: On the Role of the Rostral Dorsal Anterior Cingulate and Dorsomedial Prefrontal Cortex in Conscious Threat Appraisal, Catastrophizing, and Worrying. Neuroscience \& Biobehavioral Reviews, 42, 1-8. http://dx.doi.org/10.1016/j.neubiorev.2014.02.002

[61] Hu, Y., Chen, X., Gu, H. and Yang, Y. (2013) Resting-State Glutamate and GABA Concentrations Predict Task-Induced Deactivation in the Default Mode Network. Journal of Neuroscience, 33, 18566-18573. http://dx.doi.org/10.1523/JNEUROSCI.1973-13.2013

[62] Petersen, C.C., Hahn, T.T., Mehta, M., Grinvald, A. and Sakmann, B. (2003) Interaction of Sensory Responses with Spontaneous Depolarization in Layer 2/3 Barrel Cortex. Proceedings of the National Academy of Sciences of the United States of America, 100, 13638-13643. http://dx.doi.org/10.1073/pnas.2235811100

[63] Cossart, R., Aronov, D. and Yuste, R. (2003) Attractor Dynamics of Network UP States in the Neocortex. Nature, 423, 283-288.

http://dx.doi.org/10.1038/nature01614

[64] Lim, S.J., Wöstmann, M. and Obleser, J. (2015) Selective Attention to Auditory Memory Neurally Enhances Perceptual Precision. Journal of Neuroscience, 35, 
16094-16104. http://dx.doi.org/10.1523/JNEUROSCI.2674-15.2015

[65] Hirata, A. and Castro-Alamancos, M.A. (2010) Neocortex Network Activation and Deactivation States Controlled by the Thalamus. Journal of Neurophysiology, 103, 1147-1157. http://dx.doi.org/10.1152/jn.00955.2009

[66] McKendrick, R., Mehta, R., Ayaz, H., Scheldrup, M. and Parasuraman, R. (2017) Prefrontal Hemodynamics of Physical Activity and Environmental Complexity during Cognitive Work. Human Factors, 59, 147-162. http://dx.doi.org/10.1177/0018720816675053

[67] Rauch, A., Rainer, G. and Logothetis, N.K. (2008) The Effect of a Serotonin-Induced Dissociation between Spiking and Perisynaptic Activity on BOLD Functional MRI. Proceedings of the National Academy of Sciences of the United States of America, 105, 6759-6764. http://dx.doi.org/10.1073/pnas.0800312105

[68] Mahmoodi, M., Abadi, B.M., Khajepur, H. and Harirchian, M.H. (2017) A Robust Beamforming Approach for Early Detection of Readiness Potential with Application to Brain-Computer Interface Systems. The 39th Annual International Conference of the IEEE Engineering in Medicine and Biology Society, Jeju Island, 11-15 July 2017, 2980-2983. http://dx.doi.org/10.1109/EMBC.2017.8037483

[69] Liebrand, M., Pein, I., Tzvi, E. and Krämer, U.M. (2017) Temporal Dynamics of Proactive and Reactive Motor Inhibition. Frontiers in Human Neuroscience, 11, 204. http://dx.doi.org/10.3389/fnhum.2017.00204

[70] Menon, V. and Uddin, L.Q. (2010) Saliency, Switching, Attention and Control: A Network Model of Insula Function. Brain Structure and Function, 214, 655-667. http://dx.doi.org/10.1007/s00429-010-0262-0

[71] Nicol, R.M., Chapman, S.C., Vértes, P.E., Nathan, P.J., Smith, M.L., Shtyrov, Y. and Bullmore, E.T. (2012) Fast Reconfiguration of High-Frequency Brain Networks in Response to Surprising Changes in Auditory Input. Journal of Neurophysiology, 107, 1421-1430. http://dx.doi.org/10.1152/jn.00817.2011

[72] Wen, X., Zhang, D., Liang, B., Zhang, R., Wang, Z., Wang, J., Liu, M. and Huang, R. (2015) Reconfiguration of the Brain Functional Network Associated with Visual Task Demands. PLoS ONE, 10, e0132518. http://dx.doi.org/10.1371/journal.pone.0132518

[73] Salimpoor, V.N., Benovoy, M., Larcher, K., Dagher, A. and Zatorre, R.J. (2011) Anatomically Distinct Dopamine Release during Anticipation and Experience of Peak Emotion to Music. Nature Neuroscience, 14, 257-262. http://dx.doi.org/10.1038/nn.2726

[74] Nagano-Saito, A., Lissemore, J.I., Gravel, P., Leyton, M., Carbonell, F. and Benkelfat, C. (2017) Posterior Dopamine D2/3 Receptors and Brain Network Functional Connectivity. Synapse, 71, e21933 http://dx.doi.org/10.1002/syn.21993

[75] Kahnt, T. and Tobler, P.N. (2017) Dopamine Modulates the Functional Organization of the Orbitofrontal Cortex. Journal of Neuroscience, 37, 1493-1504. http://dx.doi.org/10.1523/JNEUROSCI.2827-16.2016

[76] Lindahl, M. and Hellgren Kotaleski, J. (2017) Untangling Basal Ganglia Network Dynamics and Function: Role of Dopamine Depletion and Inhibition Investigated in a Spiking Network Model. eNeuro, 3, pii: ENEURO.0156-16.2016. http://dx.doi.org/10.1523/ENEURO.0156-16.2016

[77] Samu, D., Seth, A.K. and Nowotny, T. (2014) Influence of Wiring Cost on the Large-Scale Architecture of Human Cortical Connectivity. PLoS Computational Biology, 10, e1003557. http://dx.doi.org/10.1371/journal.pcbi.1003557 
[78] Jarman, N., Steur, E., Trengove, C., Tyukin, I.Y. and van Leeuwen, C. (2017) Self-Organisation of Small-World Networks by Adaptive Rewiring in Response to Graph Diffusion. Scientific Reports, 7, Article Number: 13158. http://dx.doi.org/10.1038/s41598-017-12589-9

[79] Berman, B.D., Smucny, J., Wylie, K.P., Shelton, E., Kronberg, E., Leehey, M. and Tregellas, J.R. (2016) Levodopa Modulates Small-World Architecture of Functional Brain Networks in Parkinson's Disease. Movement Disorders, 31, 1676-1684. http://dx.doi.org/10.1002/mds.26713

[80] Achard, S. and Bullmore, E. (2007) Efficiency and Cost of economical Brain Functional Networks. PLoS Computational Biology, 3, e17. http://dx.doi.org/10.1371/journal.pcbi.0030017

[81] Perri, R.L., Berchicci, M., Lucci, G., Spinelli, D. and Di Russo, F. (2016) How the Brain Prevents a Second Error in a Perceptual Decision-Making Task. Scientific Reports, 6, Article Number: 32058. http://dx.doi.org/10.1038/srep32058

[82] Schiffler, B.C., Bengtsson, S.L. and Lundqvist, D. (2017) The Sustained Influence of an Error on Future Decision-Making. Frontiers in Psychology, 8, 1077. http://dx.doi.org/10.3389/fpsyg.2017.01077

[83] Barke, A., Bode, S., Dechent, P., Schmidt-Samoa, C., Van Heer, C. and Stahl, J. (2017) To Err Is (Perfectly) Human: Behavioural and Neural Correlates of Error Processing and Perfectionism. Social Cognitive and Affective Neuroscience, 12, 1647-1657. http://dx.doi.org/10.1093/scan/nsx082

[84] Bera, S., De Tomasi, G., Weiner, F. and Evers, F. (2017) Density Propagator for Many-Body Localization: Finite-Size Effects, Transient Subdiffusion, and Exponential Decay. Physical Review Letters, 118, 196801. http://dx.doi.org/10.1103/PhysRevLett.118.196801 


\section{Appendix}

\section{Abbreviation Collection}

\begin{tabular}{|c|c|}
\hline Abbreviation & Term \\
\hline CEN & Central executive network \\
\hline $\mathrm{CNV}$ & Contingent negative variation \\
\hline CR & Correct response \\
\hline DBA & Deep brain activity \\
\hline DLPFC & Dorsolateral prefrontal cortex \\
\hline $\mathrm{DMN}$ & Default mode network \\
\hline ECoG & Electrocorticogram \\
\hline EEG & Electroencephalogram \\
\hline ER-DBA & Event-related deep brain activity \\
\hline ERP & Event-related potential \\
\hline GABA & $\gamma$-aminobutyric acid \\
\hline IPFC & Inferior prefrontal cortex \\
\hline IPS & Intra-parietal sulcus \\
\hline IR & Incorrect response \\
\hline NR & No response \\
\hline NRT & Noun repetition task \\
\hline PCC & Posterior cingulate cortex \\
\hline PDF & Probability density function \\
\hline PES & Post error slowing \\
\hline $\mathrm{SN}$ & Salience network \\
\hline VGT & Verb generation task \\
\hline VTA & Ventral tegmental area \\
\hline aIC & Anterior insular cortex \\
\hline dACC & Dorsal anterior cingulate cortex \\
\hline fMRI & Functional magnetic resonance imaging \\
\hline
\end{tabular}

